\title{
Validation of Molecular Markers Genetically Linked to $S$-Cytoplasm and Restoration-of-fertility (Rf) Loci in Hot Pepper (Capsicum annuum L.)
}

\author{
Jessy Mol K.K., Lakshmana Reddy D.C., Manoj Y.B. and Madhavi Reddy K.* \\ ICAR- Indian Institute of Horticultural Research, Bengaluru-560 089, India \\ Corresponding author Email : kmreddy14@gmail.com
}

\begin{abstract}
Existence of CGMS system in hot pepper is due to the rearrangements in the mitochondrial genome and is largely used in economized and pure $F_{1}$ hybrid seed production around the world. The orf 456 , a new ORF present at flanking region of the coxII gene at the 3' end, was distinguished male sterile cytoplasm in hot peppers along with atp6-2gene. In the current study, eighteen pepper genotypes (nine each of $A$ and corresponding $B$ lines) of varied origin were used to validate with two male sterile cytoplasm ( $S$-cytoplasm) specific sequence characterised amplified region (SCAR) markers $v i z ., a t p 6-2_{(875 b p)}$ and $o r f 456_{(456 b p)}$ and one restoration-of-fertility $(R f)$ locus specific marker, $\mathrm{CRF}_{(550 \mathrm{~b})}$. The results clearly showed that the presence of $\mathrm{CMS}-\mathrm{S}$-cytoplasm and absence of restoration-of-fertility $(R f)$ gene in the pepper genotypes studied and is comparable with the phenotypic data. In view of the outcomes it has been reasoned that the accessible $\boldsymbol{S}$ and $\boldsymbol{R} \boldsymbol{f}$ markers available in the public domain are reproducible and can be promptly utilized for marker assisted selection (MAS) in hot pepper crop improvement program.
\end{abstract}

Keywords: CGMS, Hot pepper, Marker Assisted Selection, Mitochondria, ORF.

\section{INTRODUCTION}

Peppers are commercially grown as a spice and vegetable crop. Hot pepper is a Solanaceous crop, originated in Central and South America, and is introduced to India over 500 years ago.Among the domesticated species, Capsicum annuum $\mathrm{L}$ is one of the most extensively cultivated pepper species in India. In India, $75 \%$ of chilli production is from the southern states viz., Andhra Pradesh, Telangana, Karnataka, Tamil Nadu and Maharashtra. Concerted efforts in thecrop improvement program in pepper resulted in release of many improved varieties and $\mathrm{F}_{1}$ hybrids for commercial cultivation. Utilization of male sterile systems in $F_{1}$ hybrid seed production of peppers is exceptionally economical.

Male sterility in crops is due to a failure to produce functional pollen or anthers (Grelonet al., 1994, Pruitt and Hanson, 1991; Budar and Pelletier, 1994). CMS/ CGMS is exploited for the development of F1 hybrids in many crops around the world (Hanson, 1991; Hanson and Bentolia, 2004; Miller and Bruns, 2016). Generally,CMS resulted due to the rearrangements in the mitochondrial genome sequences, which in turn results in the arrangement ofnew open reading frames (ORF) which alter the expression of normal genes of the mitochondrial ATP synthesis complex (Pruitt and Hanson,1991; Budar and Pelletier, 1994). The rearrangements within the sub unit genes of ATP synthesis, such as atp 4, 6, 8 and 9 (Pruitt and Hanson, 1991; Hanson and Bentolia, 2004; Schanable and Wise, 1998 Pruitt and Hanson, 1989) are responsible for the CMS in crops and other gene rearrangements observed in pepper lines will be contributed by coxII and nad 9 .

Hot pepper genotype PI164835, a collection from India was the first CMS line reported (Peterson, 1958), and is being used in production of $\mathrm{F}_{1}$ hybrid seeds all over the world (Reddy et al., 2002). In this CMS line, a new ORF viz., orf456 was found as flanking region of the coxII gene at the 3' end. The atp6-2 gene is believed to be regulated through restoration-of-fertility $(R f)$ loci at the transcriptional level and the orf456 is regulated at post transcriptional or translational level 
Validation of DNA markers

Table 1. Molecular markers used for the validation of male sterile lines in the present study

\begin{tabular}{|l|l|c|c|c|}
\hline $\begin{array}{l}\text { Marker } \\
\text { name } \\
\text { (Nature) }\end{array}$ & Primer Sequence (52 to 32) & $\begin{array}{c}\text { Annealing } \\
\text { temperature } \\
\left({ }^{\circ} \mathbf{C}\right)\end{array}$ & $\begin{array}{c}\text { Expected } \\
\text { amplicon size of } \\
\text { primer (bp) }\end{array}$ & Reference \\
\hline $\begin{array}{l}\text { atp6-2 } \\
\text { (SCAR) }\end{array}$ & $\begin{array}{l}\text { F AGTCCACTTGAACAATTTGAAATAATC } \\
\text { R - GTTCCGTACTTTACTTACGAGC }\end{array}$ & 58 & $875 \mathrm{bp}$ & $\begin{array}{c}\mathrm{Ji} \text { et al. } \\
(2013)\end{array}$ \\
\hline $\begin{array}{l}\text { orf456 } \\
\text { (SCAR) }\end{array}$ & $\begin{array}{l}\text { F - ATGCCCAAAAGTCCCATGTA } \\
\text { R - TTACTCGGTTGCTCCATTGTTT }\end{array}$ & 60 & $456 \mathrm{bp}$ & $\begin{array}{c}\text { Kim } \text { et al. } \\
(2007)\end{array}$ \\
\hline $\begin{array}{l}\text { CRF } \\
\text { (SCAR) }\end{array}$ & $\begin{array}{l}\text { F - GTACACACCACTCG-TCGCTCCT } \\
\text { R - TTCTTGGGTCCCTTT-CTTCCAA }\end{array}$ & 55 & $870 \mathrm{bp}$ & $\begin{array}{c}\text { Gulyas } \text { et al. } \\
(2006)\end{array}$ \\
\hline
\end{tabular}

(Kim et al., 2006; Kim et al., 2007), are responsible for CMS trait.In the present study, the four stable CGMS lines developed and being use dinpepper improvement program at ICAR-IIHR, Bangalore are validated with the two male sterile cytoplasm $(S$ cytoplasm) trait linked markers, atp6-2 and orf456 and one restoration-of-fertility $(R f)$ loci linked to $C R F$ marker.

\section{MATERIALS AND METHOD}

\section{Plant material}

An aggregate of nine male sterile and their comparing nine maintainer lines were utilized in the current study are referenced in the Table 2.

\section{Phenotypic evaluation of male sterility}

The phenotypic evaluation of male sterility and fertility in lines were carried out by the visual observation at the flowering stage. The male sterile plants showed no pollen grains with shriveled anther lobes, whereas the male fertile plants have bulged anther lobes with abundant pollen grains (Plate 1).

\section{Pollen morphologyandsize}

The freshly unopened flower samples of male sterile and male fertile plants were gathered from the field in the early dawn,and put away in impenetrable zip lock polythene covers over the ice package to keep up the freshness. The pollen grains were collected from the dehisced anther lobes independently from individual flowers, frozen on the liquid nitrogen and stored them at $-195^{\circ}$ for further studies. For morphological examinations, the individual pollen grains were directly dusted on to the slides and length and breadth of the individual grains were measured using scanning electronmicroscope (TM3000, Hitachi, Japan). The reproductive parts of both male sterile and male fertile flowers and the cross section of the anther lobes were additionally seen under the scanning electronmicroscope (TM3000, Hitachi, Japan), in order to study the morphological difference between the male sterile and male fertile flowers. The stereo microscopy images of the dehisced flowers were additionally examined (ZEISS Stereo zoom microscope Stemi 508 doc, Germany).

\section{DNA extraction:}

The total genomic DNA was isolated from the leaves of one month old seedling using 4\% CTAB plant extraction protocol (Doyle and Doyle, 1990). The genomic DNA samples were qualitatively checked in $0.8 \%$ agarose gel and quantitatively by using UVspectrophotometer. The concentrated DNA was diluted to $20 \mathrm{ng} / \mu \mathrm{L}$ according to the spectrophotometer reading and thus diluted DNA is used as the template in PCR for genotyping with specific molecular markers.

\section{PCR conditions and validation of molecular markers:}

The polymerase chain reaction master mixture contained $2 \mu \mathrm{L}$ of $10 \mathrm{X}$ buffer, $2 \mu \mathrm{L} 25 \mathrm{mM} \mathrm{MgCl}_{2}$, $2.5 \mu \mathrm{L} 1 \mathrm{mM}$ dNTP, (3b Blackbio, Spain ) $1.5 \mu \mathrm{L}$ of $10 \mu \mathrm{M}$ of forward and reverse primer, $0.5 \mu \mathrm{L} 1 \mathrm{U} \mathrm{Taq}$ DNAPolymerase (3b Blackbio, Spain) and $2 \mu \mathrm{L}$ of 20ng template DNA. The PCR conditions for the validation of the three SCAR markers were carried out as mentioned here. Initial denaturation at $95^{\circ}$ for 5 minutes accompanied with 30 repeated cycles of denaturation at $94^{\circ}$ for 60 seconds, annealing as given in the Table 1 for 60 seconds, extension at $72^{\circ}$ for 60 seconds and final extension at $72^{\circ}$ for 5 minutes. The reactions were carried out in the thermocycler (Eppendorf, Germany). PCR amplified fragments were separated on $1.5 \%$ agarose gel/1X TBE (w/ vol), stained with ethidium bromide dye and 
Table 2. Results of the markers screened for CGMS lines

\begin{tabular}{|c|c|c|c|c|c|c|}
\hline \multirow{2}{*}{ Sl.No. } & \multirow{2}{*}{ Sample Name } & \multicolumn{3}{|c|}{ PCR Amplification of SCAR markers } & \multirow{2}{*}{$\begin{array}{l}\text { Observed } \\
\text { Phenotype }\end{array}$} & \multirow{2}{*}{$\begin{array}{l}\text { Expected } \\
\text { Genotype }\end{array}$} \\
\hline & & atp6-2 & orf 456 & CRF & & \\
\hline \multicolumn{7}{|c|}{ Male sterile lines } \\
\hline 1 & IIHR $3285 \mathrm{~A}$ & + & + & - & Sterile & $\mathrm{S}$ \\
\hline 2 & IIHR $3226 \mathrm{~A}$ & + & + & - & Sterile & $\mathrm{S}$ \\
\hline 3 & IIHR 3287 A & + & + & - & Sterile & $\mathrm{S}$ \\
\hline 4 & IIHR $3228 \mathrm{~A}$ & + & + & - & Sterile & $\mathrm{S}$ \\
\hline 5 & IIHR $4560 \mathrm{~A}$ & + & + & - & Sterile & $\mathrm{S}$ \\
\hline 6 & IIHR $4561 \mathrm{~A}$ & + & + & - & Sterile & $\mathrm{S}$ \\
\hline 7 & IIHR $4558 \mathrm{~A}$ & + & + & - & Sterile & $\mathrm{S}$ \\
\hline 8 & IIHR 4553 A & + & + & - & Sterile & $\mathrm{S}$ \\
\hline 9 & IIHR $4555 \mathrm{~A}$ & + & + & - & Sterile & $S$ \\
\hline \multicolumn{7}{|c|}{ Male fertile lines } \\
\hline 10 & IIHR 3285 B & - & - & - & Fertile & $\mathrm{N}$ \\
\hline 11 & IIHR 3226 B & - & - & - & Fertile & $\mathrm{N}$ \\
\hline 12 & IIHR 3287 B & - & - & - & Fertile & $\mathrm{N}$ \\
\hline 13 & IIHR 3228 B & - & - & - & Fertile & $\mathrm{N}$ \\
\hline 14 & IIHR 4560 B & - & - & - & Fertile & $\mathrm{N}$ \\
\hline 15 & IIHR 4561 B & - & - & - & Fertile & $\mathrm{N}$ \\
\hline 16 & IIHR 4552 B & - & - & - & Fertile & $\mathrm{N}$ \\
\hline 17 & IIHR 4554 B & - & - & - & Fertile & $\mathrm{N}$ \\
\hline 18 & IIHR 4556 B & - & - & - & Fertile & $\mathrm{N}$ \\
\hline 19 & Control R- line & - & - & + & Fertile & $\mathrm{N}$ \\
\hline
\end{tabular}

(+) amplification; (-) non-amplification

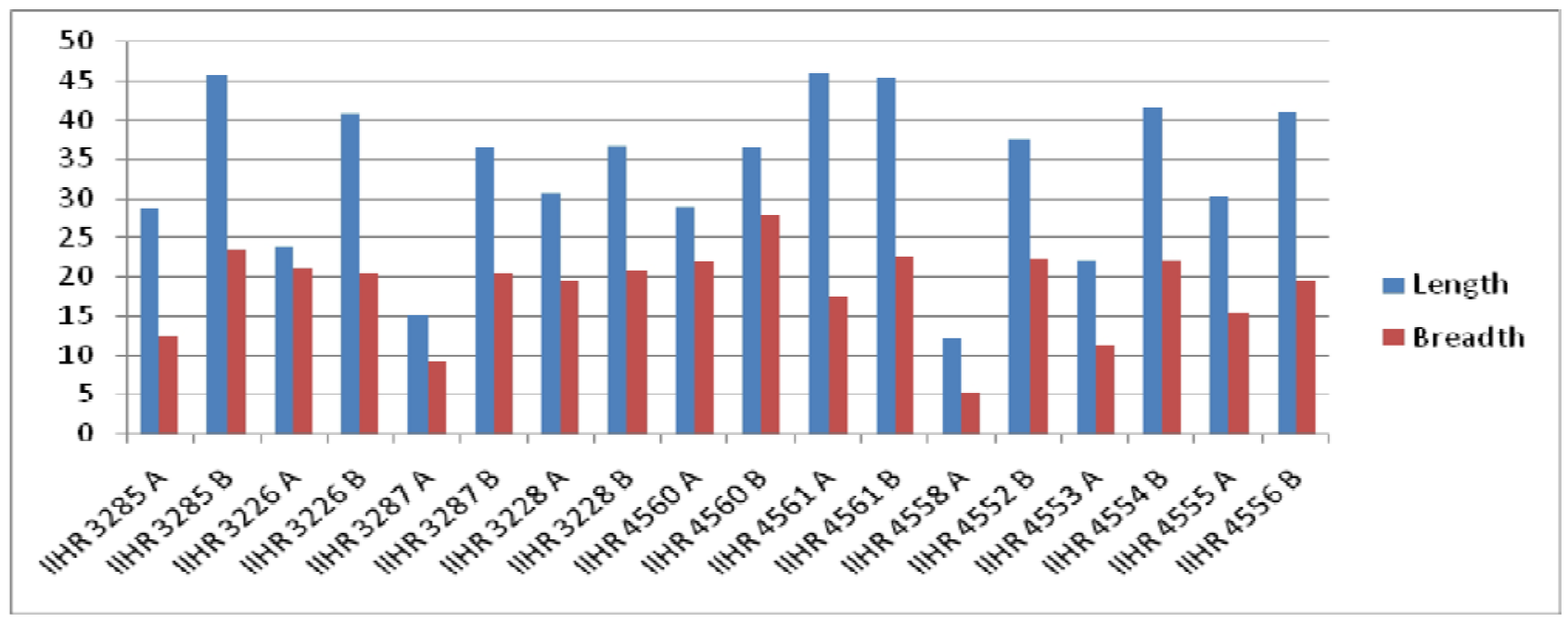

Fig 1. Bar diagram showing the measurement of individual pollen grains size in male sterile vs male fertile flowers using scanning electron microscope 
documented under neath the ultra violet light (UVI Pro Platinum, Cambridge, U.K). The experiments were repeated for three consecutive times with each marker for confirmation of results.

\section{Cloning and sequencing:}

The PCR amplified fragments of atp6-2 gene in male sterile lines were separated on $1 \%$ agarose stained with $\mathrm{EtBr}$ gel, excised and purified the fragments using Nucleospin ${ }^{\circledR}$ Gel and PCR Clean-Up Kit (Macherey-Nagel, Germany). Five $\mu \mathrm{L}$ of the eluted product was ligated into pTZ57RT cloning vector system. The pTZ57RT vector containing the ligated DNA was successfully transformed into DH5 $\alpha$ strain of E.coli. Transformed colonies were spread on Luria Bertani agar/Ampicillin/X-gal/IPTG plates and were identified through blue white screening after incubation at $37^{\circ}$ overnight. Recombinant colonies were confirmed using colony PCR, further plasmid was isolated using alkaline lysis method. The isolated plasmids were confirmed for the presence of insert (atp6-2 gene) by digestion with the restriction enzyme, EcoRI and the restriction digested products were separated on $1 \%$ agarose/ $\mathrm{EtBr}$ gel to differentiate two distinct bands of vector and the $850 \mathrm{bp}$ insert respectively. Before sequencing, PCR product clean-up was performed using Nucleospin ${ }^{\circledR}$ Gel and PCR Clean-Up Kit (MachereyNagel, Germany). The sequencing was carried out in ABI-3710 Prison automated DNA analyzer (Europhins, India).

\section{RESULTS AND DISCUSSION}

We used two male sterile cytoplasm ( $S$-cytoplasm) trait linked markers, atp 6-2 875 and orf456(Ji et al.,2013and Kim et al., 2005, 2007) and one restoration-of-fertility $(R f)$ loci linked marker $C R F$ (Gulyas et al.,2006) to validate nine male sterile and their corresponding nine maintainer lines. CMS linked SCAR markerorf456 amplified in allthe male sterile genotypes ( $S$-cytoplasm), at an expected base pairs of 456 as shown in the Fig. 2 and this 456bp amplicon size was absent in all corresponding maintainer lines ( $N$-cytoplasm) (Fig.2c, Table 2).Instead of amplifying at expected amplicon size of $875 \mathrm{bp}$, atp6-2 marker amplified at $850 \mathrm{bp}$ in all the nine male sterile genotypes ( $S$-cytoplasm) (Fig.2b, Table 2).In order to confirm the $25 \mathrm{bp}$ difference in the amplicon size, further cloning and sequencing was undertaken. Five clones each of the male sterile lines were selected, plasmid isolated, purified and further sequenced (ABI3710 Prisom automated DNA analyzer). Sequence obtained from ABI-3710 Prisom automated DNA analyzer was analysed from NCBI site (www.ncbi.nlm.nih.gov) and checked for nucleotide sequence identity of the observed sequences and found that there is almost $99 \%$ identity for Capsicum annuum atp6-2 subunit.The presence of the expected amplicon pattern in all nine male sterile genotypes $(S$ cytoplasm) proved that the mitochondrial gene associated atp6-2 subunit is responsible for the transcription of the orf456 novel gene which indeed responsible for the cause of CMS in the cultivar varieties of hot peppers. Meanwhile, the nine corresponding male fertile/ maintainer lines $(\mathrm{N}$ cytoplasm) failed to amplify at the expected amplicon size. The CMS lines which are phenotypically male sterile are genotypically carrying a sterile cytoplasm, $S$ with $r f r f$ loci and all the maintainer or fertile B lines are genotypically carrying a normal cytoplasm, $\mathrm{N}$ with $r f r f$ loci.The one $C R F-S C A R$ marker specific to restoration-of-fertility $(R f)$ locus as expected failed to amplify the $550 \mathrm{bp}$ fragment in any of the nine cytoplasmic male sterile (A) lines or cytoplasmic male fertile/maintainer (B) lines (Fig 2, Table 2). The complete absence of the $C R F-S C A R$ marker in all genotypes used for the current study proves that these samples didn't carry a restoration-of-fertility, $R f$ loci, indicating that the cytoplasm looks genotypically normal, $\mathrm{N}$ or sterile, $\mathrm{S}$. Even though there are markers for identification of restoration-of-fertility (Rf) in hot pepper (Kumar et al., 2009, Kim et al., 2005, Zhang et al., 2000),CRF-SCAR marker (Gulyas et al.,2006) is the most commonly and widely used molecular marker for the detection of presence or the absence of restoration-of-fertility in CMS lines of hot pepper.

Further, using the scanning electron microscope (SEM) the morphological variation in pollen grain size among the nine male sterile and their corresponding maintainer lines (Fig.1\& Plate 2) was studied measuring the length and breadth of pollen grains (Plate 2). Maximum variation in pollen grain length was observed among A lines compared to B lines, and it ranged from 12.2 to $46.2 \mu \mathrm{M}$ and 36.4 to $45.7 \mu \mathrm{M}$, respectively. Similarly, maximum variation in pollen grain breadth was observed among A lines and ranged from 5.24 to $21.9 \mu \mathrm{M}$, whereas it ranged from 19.4 
Plate 1. Images of male sterile vs male fertile flowers

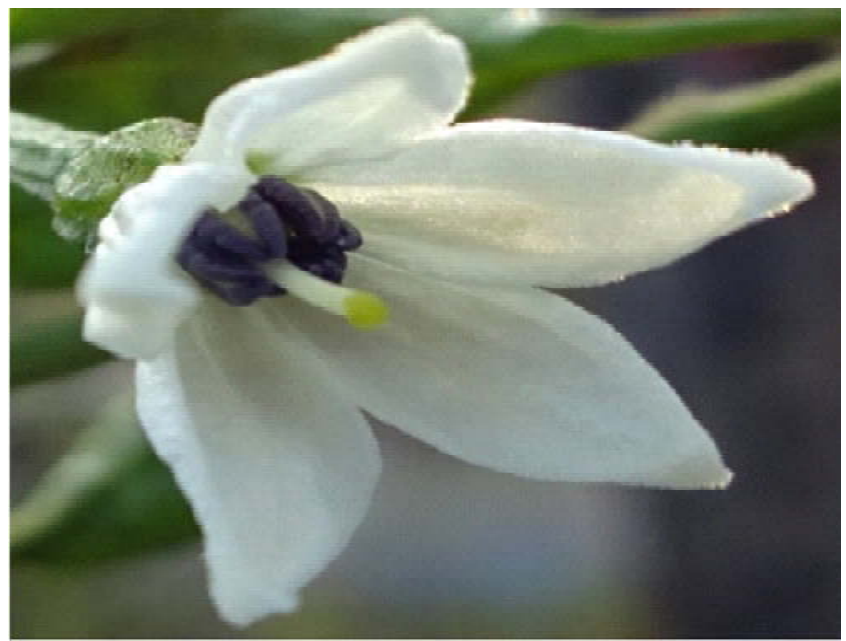

IIHR3285 A
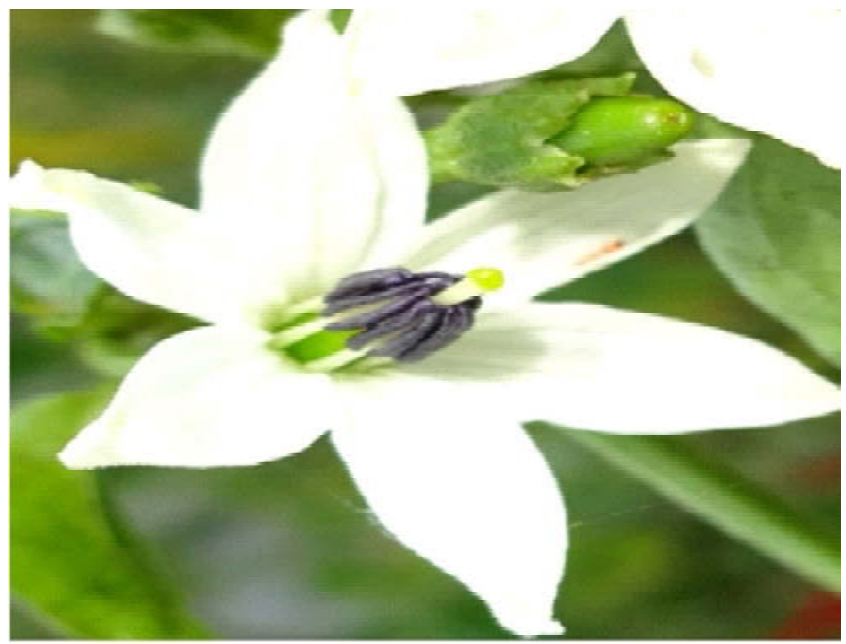

IIHR3287 A

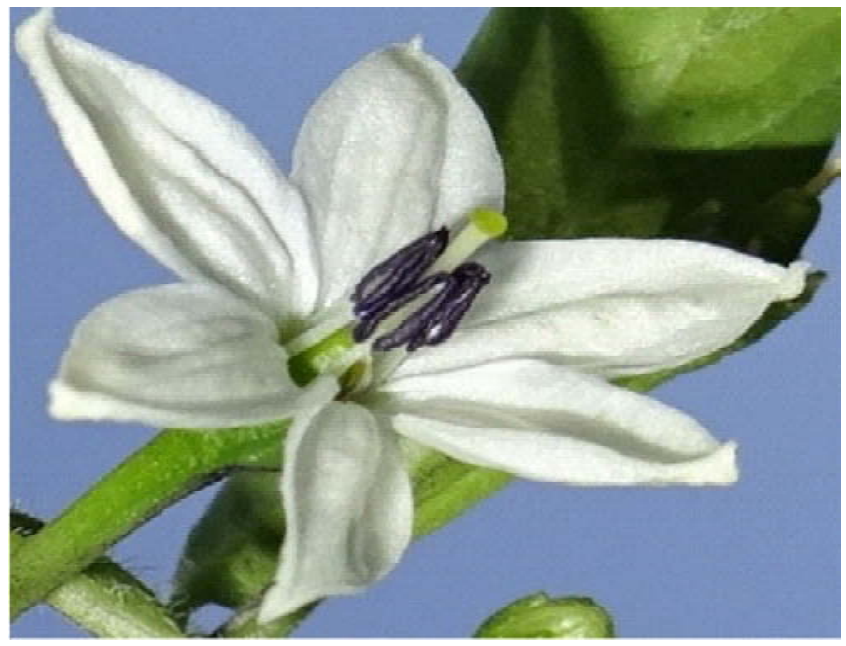

IIHR3228 A

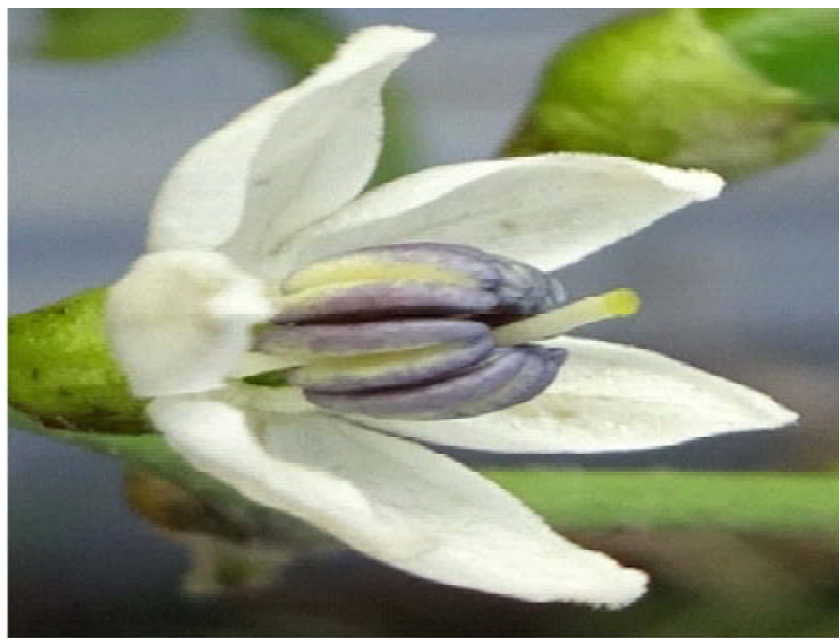

IIHR3285 B

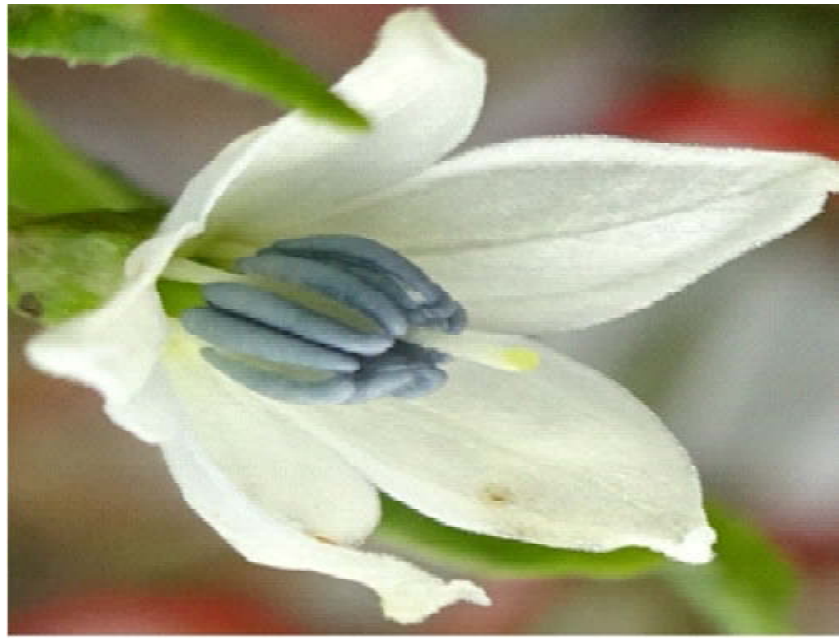

IIHR3287 B

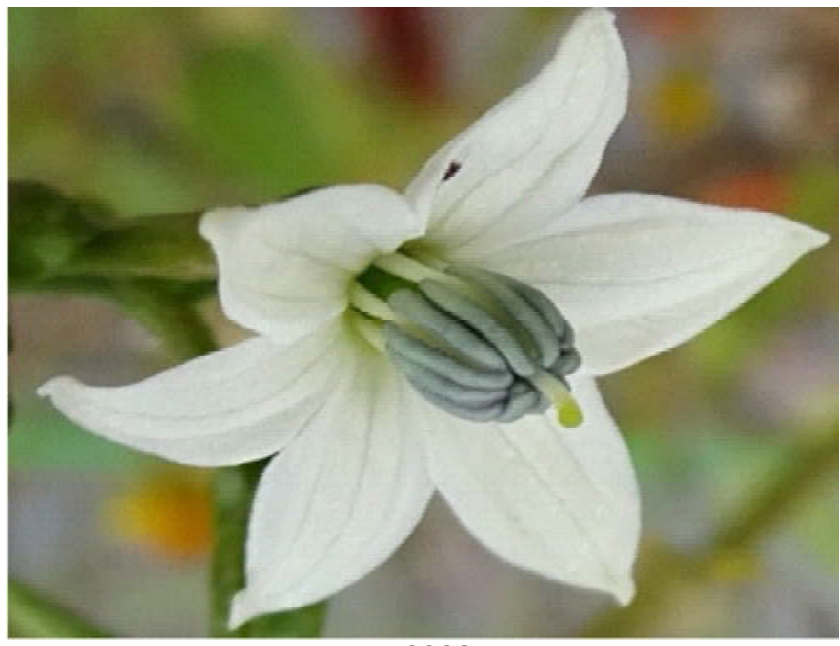

IIHR3228 B

Male sterile (A) lines showing shrinked anther

Maintainer (B) lines showing bulged anther 
Plate 2. Images of male sterile vs male fertile anthers

(Single pollen SEM images at 2.5k magnification)

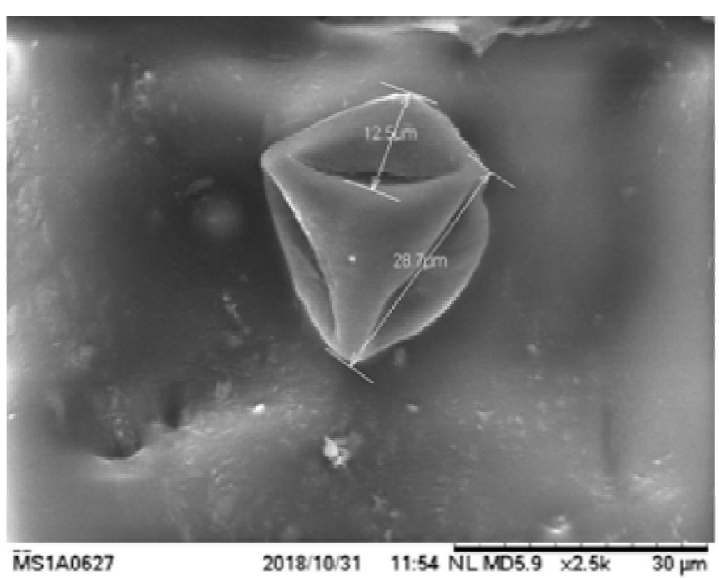

ICAR-IIHR Virology Lab

IIHR3285 A

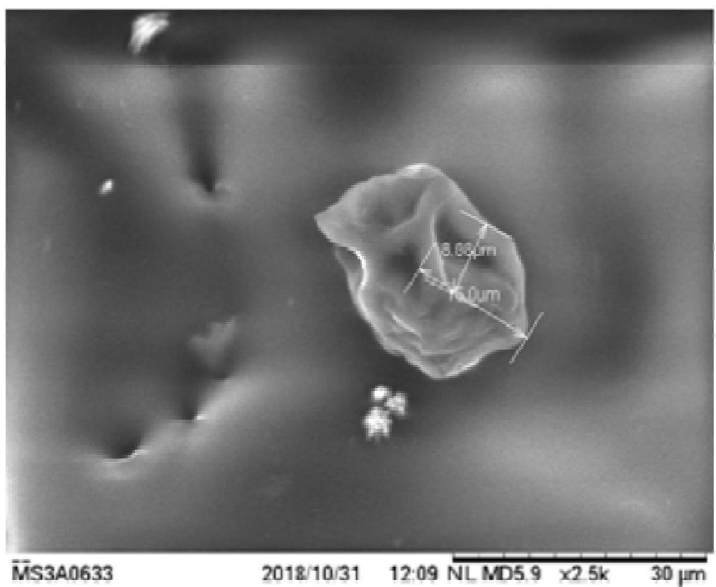

ICAR-IIHR Virology Lab

IIHR3287 A

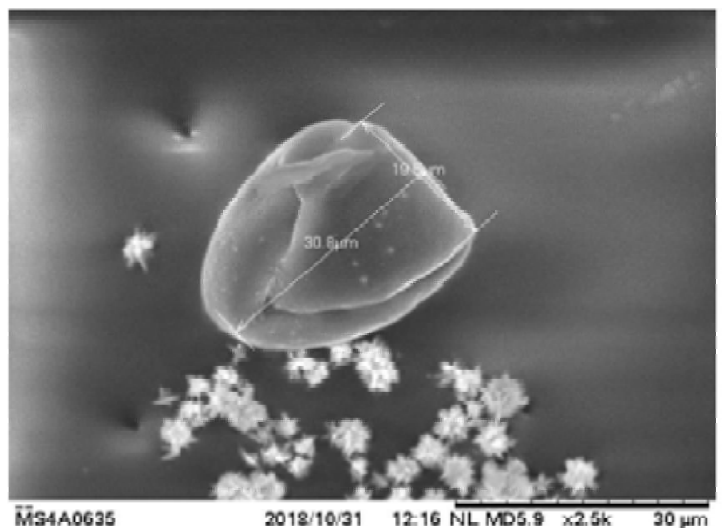

ICAR-IIHR Virolegy Lab

2018/10/31 12:16 N1059-25x

IIHR3228 A

Male sterile (A) lines showing shrinked pollen grains

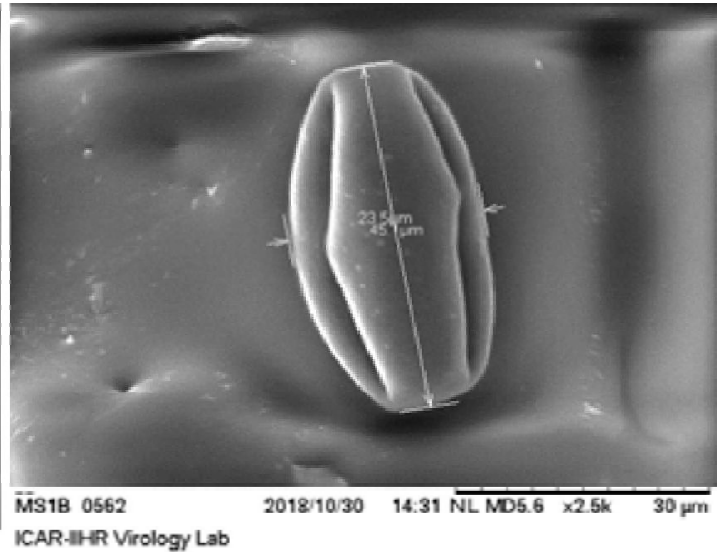

IIHR3285 B

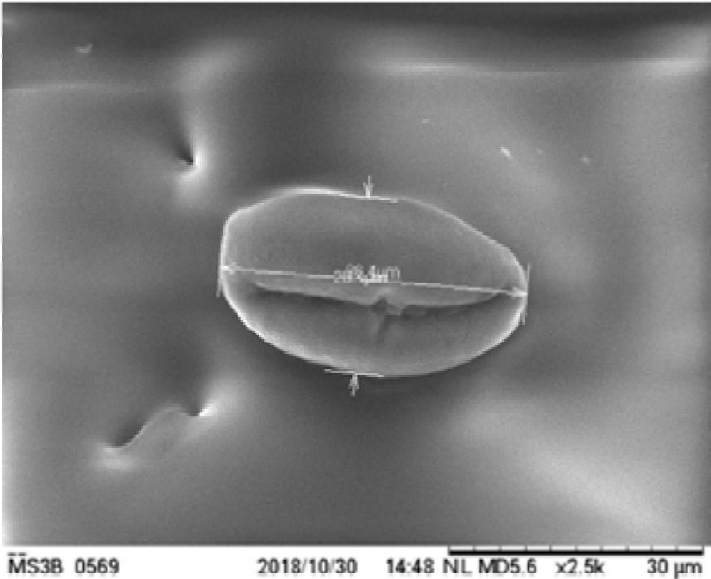

ICAR-IIHR Virology Lab

IIHR3287 B

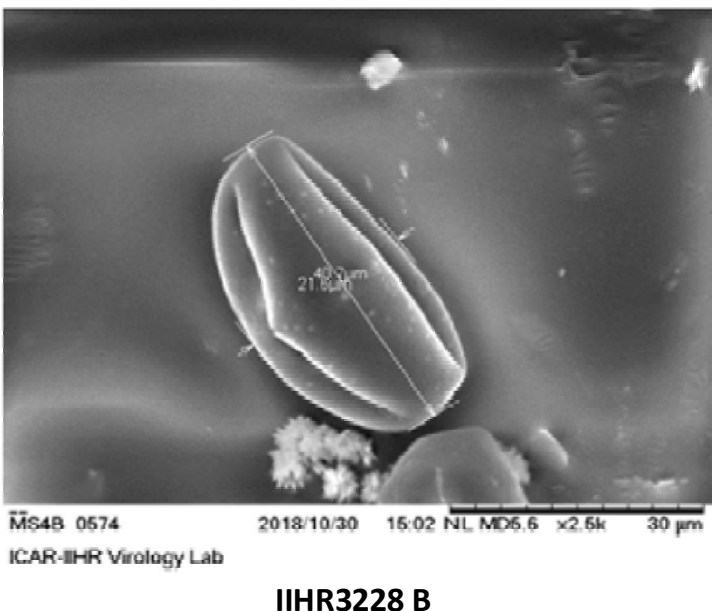

Maintainer (B) lines showing normal pollen grains 
to $27.8 \mu \mathrm{M}$ among $\mathrm{B}$ lines (Fig. 1 \& Plate 2), respectively.

The SEM images of the reproductive parts of the male sterile flowers morphologically found to be very shorter in size compared to the male fertile plants. The anther lobes of the male sterile flowers appeared to be shrivelled with less or shrunken pollen grains, whereas the male fertile plants have bulged anther lobes with abundant pollen grains (Plate $3 b$ ). So as to see the distribution of the pollen grains inside the anther lobe, the cross section of the anther lobe was studied. The SEM images clearly distinguished the male sterile plants had no visible pollens inside the tetrad pollen chambers, rather the male fertile plants produced numerous functional pollens (Plate 3c) attached to the tetrad anther chambers. The stereo

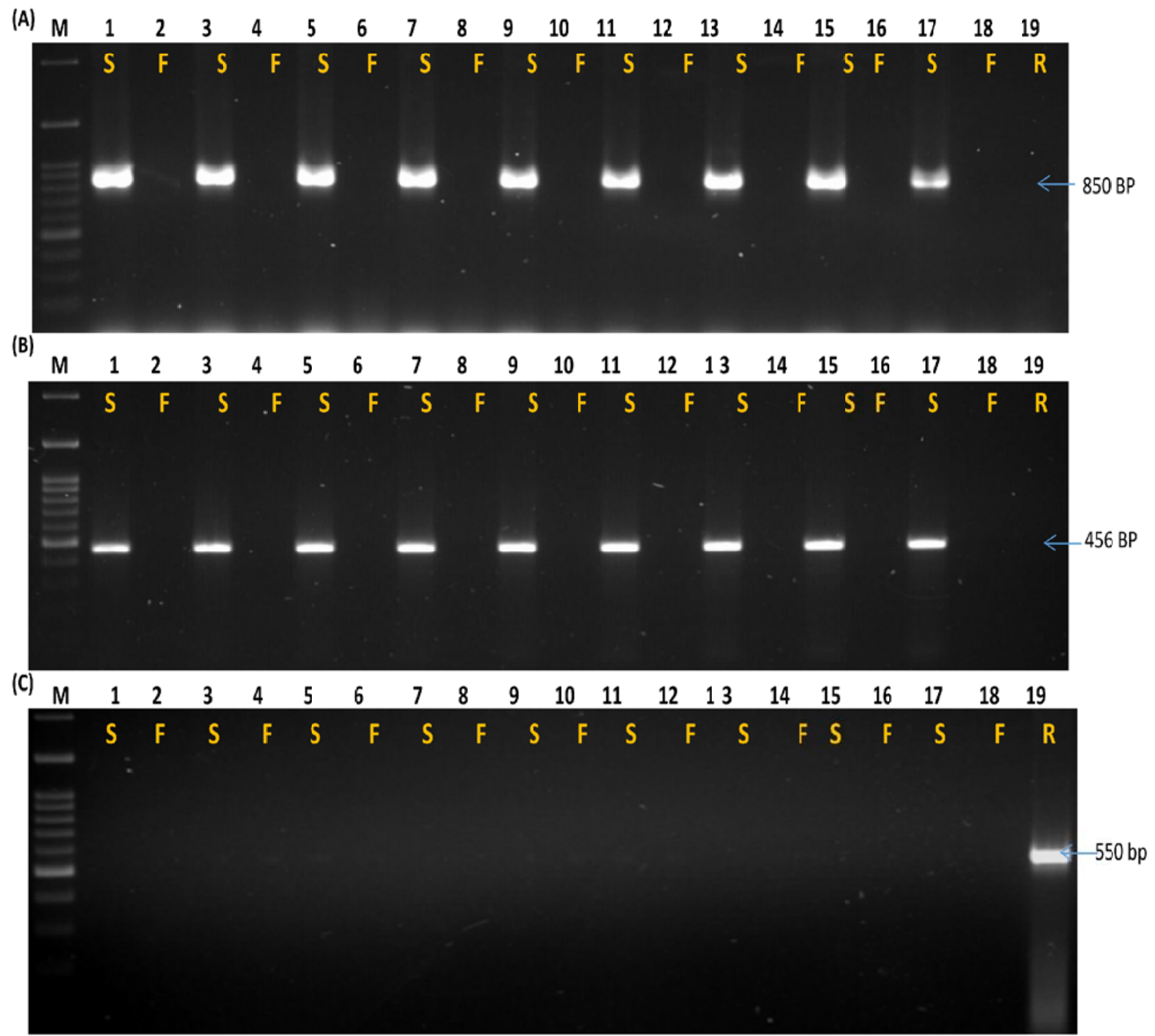

Fig 2: Gel picture showing the amplification results with the three molecular markers across eight pairs of sterile and fertile lines used (A) atp6-2 marker (B) orf 456 marker and (C) restorer of fertility gene specific crfmarker. All PCR products were separated on $1.5 \% 1 \mathrm{X}$ TAE- agarose gel, stained with ethidium bromide dye. $M=100$ bp ladder, serial number 118 indicates the sample order as given in the table no.2. $\mathrm{S}=$ male sterile line, $\mathrm{F}=$ male fertile line and $\mathrm{R}=$ restoral line. Arrow head indicates the band size obtained. 
Plate 3. Male sterile vs male fertile (a) flower, (b) reproductive part and (c) cross section of anther lobe

Male sterile
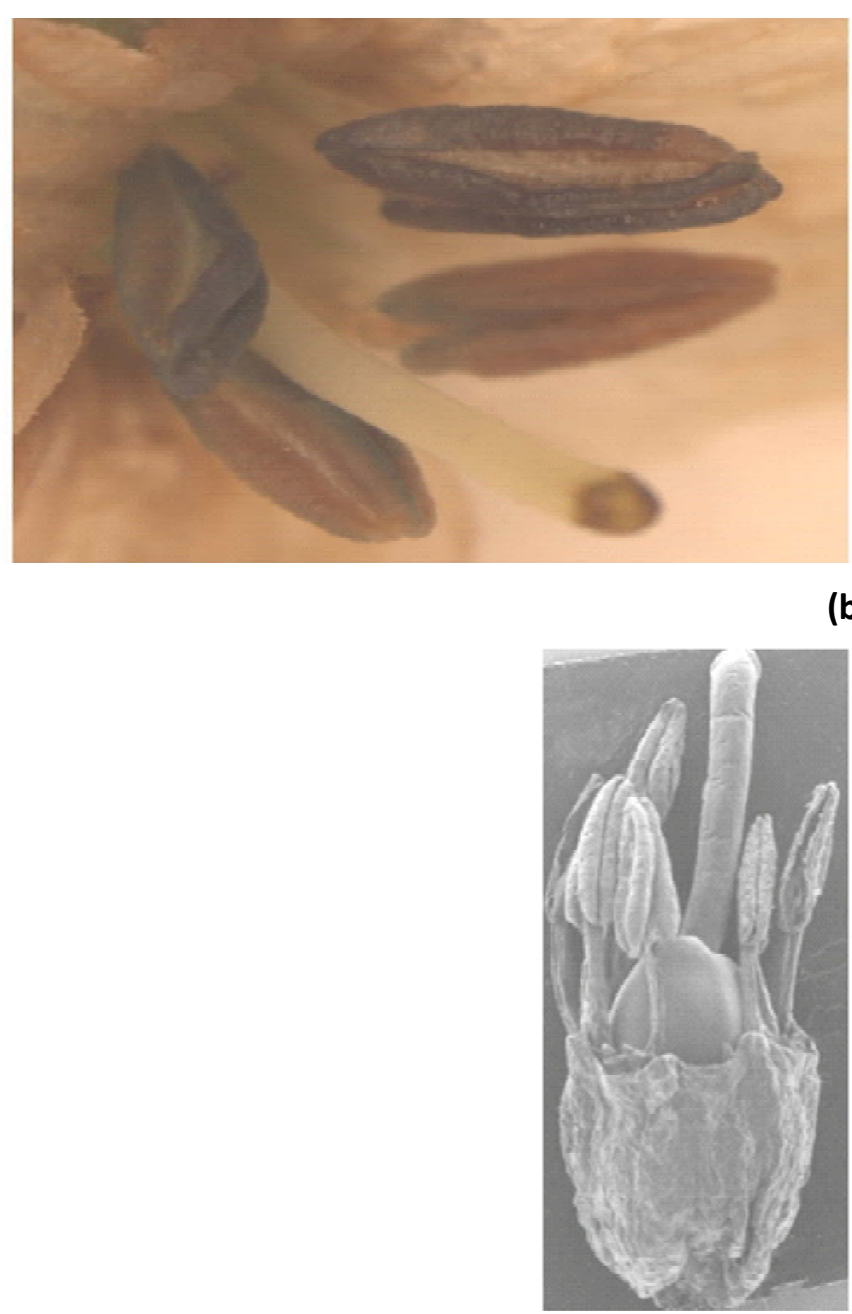

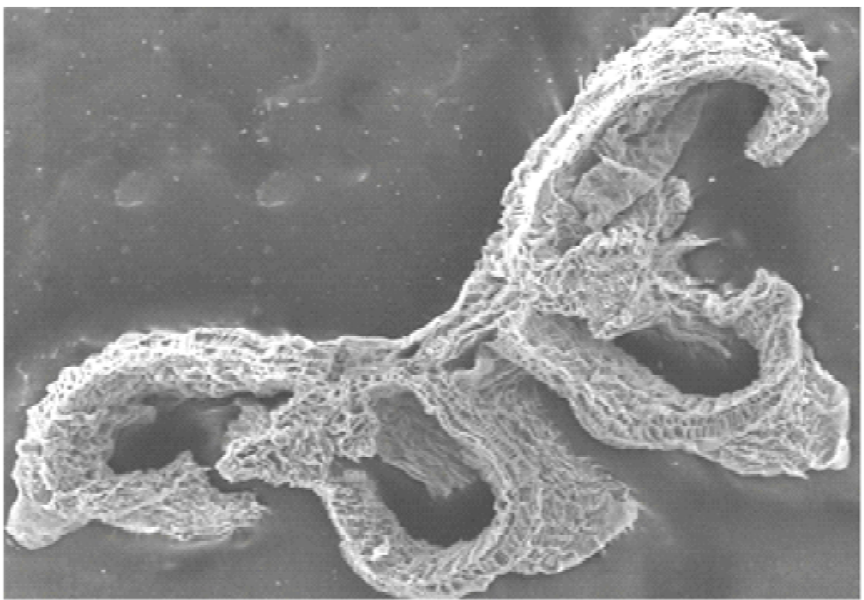

Male sterile (A) lines with no or very less pollen grains (b)

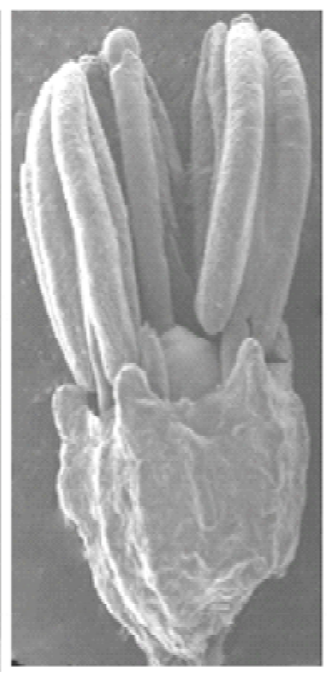

(c)

(a) Male fertile
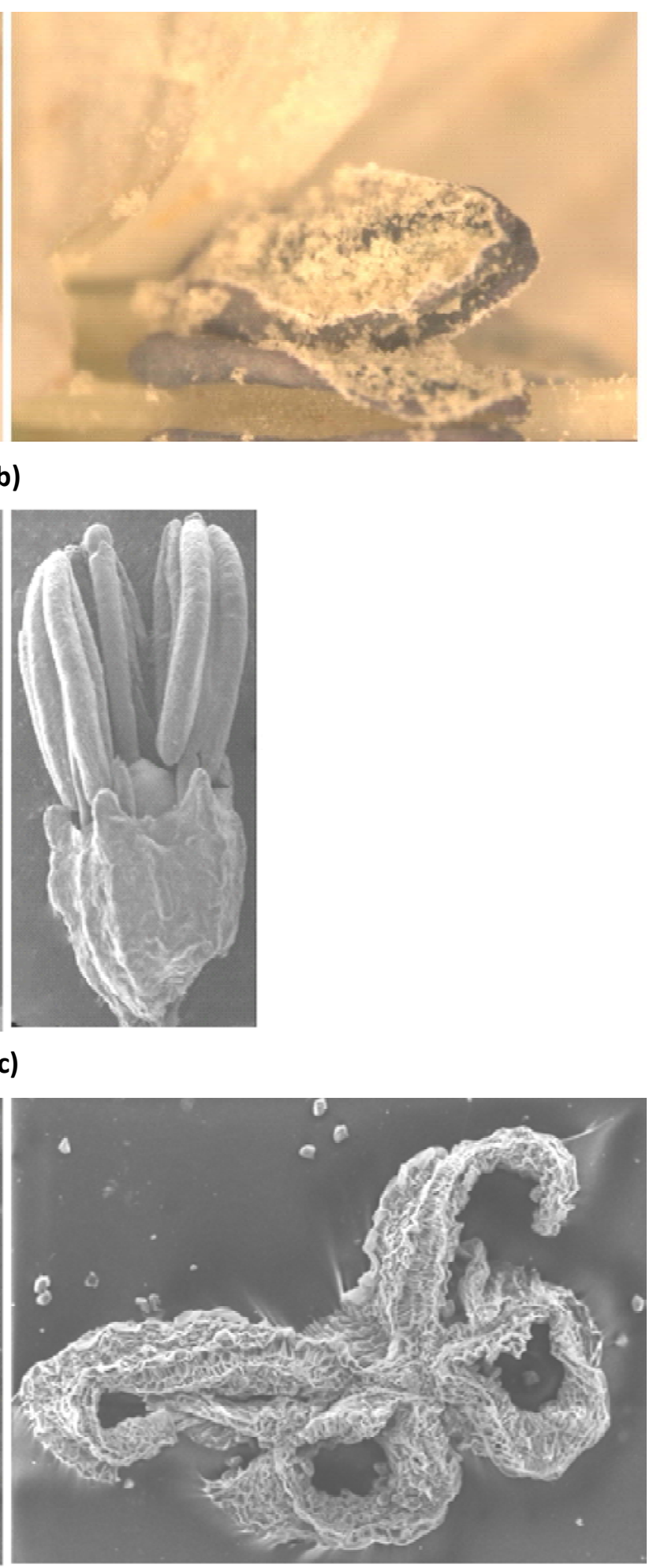

Maintainer (B) lines with abundant pollen grains 
microscopy images of the dehisced flowers clearly showed the absence of pollens at different magnification in male sterile plants where as presence of abundant pollen grains were visible in and out of the anther lobes of male fertile plants as shown on Plate 3a.

\section{CONCLUSION}

CMS in crops is caused due to a failure to produce functional pollen or anthers (Gómez 1999, Pruitt and Hanson, 1991). Previously, the two male sterile cytoplasm ( $S$-cytoplasm) trait linked molecular markers viz., atp6-2 and orf456 (Ji et al.,2013 and Kim et al.,2005,2007)were identified and characterised in CMS lines of hot pepper, were further used for the hybrid seed production in a commercial scale. The CMS pepper lines, were validated with the existing SCAR markers linked to the male sterility in pepper. The eight hot pepper lines namely IIHR 3285, IIHR 3226 , IIHR 3287, and IIHR 3228 (four CMS and 4 maintainer lines) developed at ICARIIHR, Bangalore and the other ten hot pepper lines (5 CMS and 5 maintainer lines) received from AVRDC, Taiwan, are having common sterile cytoplasm and restoration-of-fertility genes as were successfully validated using the three already known SCAR markers i.e., two male sterile cytoplasm (S-cytoplasm) trait linked to atp6-2 and orf456 (Ji et al.,2013 and Kim et al., 2005, 2007) and one restoration-of-fertility $(R f)$ loci linked marker $C R F$ (Gulyaset al.,2006) and these molecular markers are highly reproducible at the genotypic level. Thus, these molecular markerscan be effectively used to recognize CMS from maintainer lines and fertility restorer lines and helps to fasten the breeding work to incorporate the CGMS system with varied fruit types and to incorporate disease resistant genes into A, B and $\mathrm{R}$ lines.

\section{ACKNOWLEDGEMENTS}

The authors thank Indian Councilfor Agricultural Research (ICAR), New Delhi, India for providing funds under the Flagship programme on Studies on male sterility system to increase the efficiency of $F_{1}$ hybrids in horticultural crops. The authors also express a word of thanks to the Director, ICAR-IIHR for constant encouragement and support.

\section{REFERENCES}

Budar F and Pelletier G (2001) Male Sterility in Plants; Occurrence, Determinism, Significance and Use. Life Science 324: 543-550.

Doyle J J, Doyle JL (1990) Isolation ofplant DNA from fresh tissue. Focus 12:13-15.

Grelon M, Budar F, Bonhomme S, Pelletier G (1994) Ogura cytoplasmic male-sterility (CMS)associated $\operatorname{orf} 138$ is translated into a mitochondrial membrane polypeptide in male sterile Brassica cybrids. Molecular Genetics and Genomics 243:540-547

Gulyas G, Pakozdi K, Lee JS, Hirata Y (2006) Analysis of fertility restoration by using cytoplasmic male sterile red pepper (Capsicum annuum L.) lines. Breeding Science 56:331334.

Hanson MR (1991) Plant mitochondrial mutations and malesterility. Annual Review of Genetics 25:461-486
Hanson M and Bentolila S (2004) Interactions of mitochondrial andnuclear genes that affect male gametophyte development.Plant Cell 16:S154S169

Ji J J, Huang W, Yin C, Gong Z H (2013) Mitochondrial cytochrome c oxidase and F1FoATPase dysfunction in peppers (Capsicum annuum L.) with cytoplasmic male sterility and its association with orf507 and atp6-2genes. International Journal Molecular Science 14:1050-1068.

Kim DH, Kim BD (2005) Development of SCAR markers for early identification of cytoplasmic male sterility genotype in chili pepper (Capsicum annuum L.). Molecules \& Cells 20:416-422.

Kim DS, Kim DH, Yoo JY, Kim BD (2006) Cleaved amplified polymorphic sequence and amplified fragment length polymorphism markers linked to the fertility restorer gene in chili pepper (Capsicum annuum L.). Molecules \& Cells 21:135-140. 
Kim DH, Kang JG, Kim BD (2007) Isolation and characterization of the cytoplasmic male sterility-associated orf456 gene of chili pepper (Capsicum annuum L.). Plant Molecular Biology 63:519-532.

Kumar R, Kumar S, Dwivedi N, Kumar S, Rai A, Singh M, et al., (2009) Validation of SCAR markers, diversity analysis of male sterile (S-) cytoplasm and isolation of an alloplasmic Scytoplasm in Capsicum. Scientia Horticulturae. 120:167-172

Miller I and Bruns E (2016) The effect of disease on the evolution of females and the genetic basis of sex in populations with cytoplasmic male sterility. Proceedings. Biological Sciences. $283: 20153035$

Peterson P A (1958) Cytoplasmically inherited male sterility in Capsicum americana. Naturalist 92:111-119.
Pruitt K D and M R Hanson (1989) Cytochrome oxidase subunit II sequences in Petunia mitochondria: Two intron-containing genes and an intron-less pseudogene associated with cytoplasmic male sterility. Current Genetics. 16:281-291.

Pruitt K D and M R Hanson. (1991) Splicing of the Petunia cytochrome oxidase subunit II intron.Current Genetics. 19:191 197

Reddy MK., Sadashiva, A T, Deshpande, A A, (2002) Cytoplasmic male sterility in chilli (Capsicum annuum L.). Indian Journal of Genetics. 62:363-364

Schnable P S and Wise R P (1998) The molecular basis of cytoplasmic male sterility and fertility restoration. Trends in Plant Science 3:175180.

Zhang B X, Huang S W, Yang G M, Guo J Z (2000) Two RAPD markers linked to a major fertility restorer gene in pepper. Euphytica 113:155161. 